\title{
Analysis of fractal frictional contact in machining
}

\author{
S Raman*, A Basu, and D S Kilic \\ Department of Industrial Engineering, The University of Oklahoma, Norman, Oklahoma, USA
}

The manuscript was received on 14 September 2006 and was accepted after revision for publication on 30 March 2007.

DOI: $10.1243 / 09544054 J E M 740$

\begin{abstract}
A model of the interfacial frictional conditions at the secondary shear zone in oblique cutting is under development. It has been suggested that the tool-chip interface consists of sticking and sliding microcontacts, each of which exhibit dynamic variations throughout the cut. The bond strength at the interface is difficult to determine because of the unpredictable characteristic of precipitation variability and the complex behaviour of the work material under severe cutting conditions. In this research the frictional interface is investigated on a microscopic scale to shed some light on these issues. Time-dependent cutting experiments illustrate the dynamic variations in sticking and sliding. It is also proved that the sticking and sliding areas exhibit fractal characteristics. Actual contact areas for sticking and sliding were calculated by using image analysis techniques. A relationship between the fractal dimension and the area of contact is noted. A mathematical model is proposed on the basis of the measured forces and calculated contact areas.
\end{abstract}

Keywords: friction, fractals, machining, stick-slip conditions

\section{INTRODUCTION}

Friction in machining has been researched for the last 50 years, but an accurate description of the interface boundary condition is still largely unavailable. It is important to describe frictional boundary conditions in machining, since it affects many variables such as tool design, tool material selection, and cutting parameter selection. With an accurate model of the frictional boundary conditions it is also possible to determine the stress and temperature distribution, and tool wear more efficiently.

The frictional boundary conditions in machining consist of sticking and sliding interfaces, which show variability in geometry over a period of time during cutting [1]. Cutting parameters and tool and workpiece material behaviours play an important role in this variation. Macroscale assumptions of fixed geometry of sticking and sliding are questionable, since microscale effects such as surface condition, oxidation, and material properties at severe cutting conditions are not predictable. In fact, significant

*Corresponding author: Department of Industrial Engineering, The University of Oklahoma, Norman, Oklahoma, 73019, USA. email:raman@ou.edu inaccuracies could result owing to the improper consideration of the friction at the interface.

In the light of earlier studies by one of the present authors and co-workers [2-4] and other published results $[\mathbf{1}]$, it is proposed to re-examine the friction characteristics at the interface in some detail. It is logical to suggest that there exists a relationship between the bond strength between the chip and tool and the shear stress at the interface. The tool-chip interface was investigated on a microscopic scale to verify the nature of this relationship. Elemental analysis showed that the adhering material does not exhibit homogeneity at the interface, making it difficult to determine the bond strength at the interface. It is expected that careful elemental analysis combined with a proper classification of standard metalmetal, oxide-metal, and oxide-oxide bonds can allow for a theoretical calculation of the interface dynamics. This will be a subject for future research. This paper attempts to quantify contact dynamics in order to develop models for friction.

Using information about cutting forces, tool geometry, and actual areas of sticking and sliding, new modelling is proposed in this paper. Time-dependent cutting experiments helped us to observe the variation in contact during the cut. Examination of experimentally determined rake face micrographs from 
time-varying cuts strongly indicates the dynamic variation in and fractal nature of adhesion profiles. Image analysis of the same micrographs was used to determine the exact values of the sticking and sliding areas numerically. With the transformation of measured forces to the normal and shear forces on the tool rake face, a formal model can be verified with the knowledge of sticking and sliding areas and the assumed distribution of stresses.

In order to estimate the complex interfacial friction conditions between tool and chip, it is necessary to find the forces acting at the tool-chip boundary. Much research in this area has concentrated on two-dimensional orthogonal cutting. Oblique cutting analysis [5] has also been used in some cases. In practical machining, the side cutting edge, nose radius, and end cutting edge all take part in the cutting action, making the analysis more complicated. To consider their effects on cutting parameters, some published models [6] have been investigated. Based on these investigations and experimental results a need for a new model is established.

\section{EXPERIMENTAL VARIABLES}

In turning experiments, Kennametal SNG 433-K68 cutting inserts on a tool holder type of CSRNR-164 are used with a nose radius of $1.2 \mathrm{~mm}$. The cutting edge angle is $15^{\circ}$, the inclination angle is $5^{\circ}$, and the rake angle is $-5^{\circ}$. Workpieces made from the aluminium alloys $\mathrm{Al}$ 2024-T351 and $\mathrm{Al}$ 6061-T6 were used because of their good adhesion characteristics to the tool surface. The cross-sections and the tool-chip contact area were analysed using scanning electron microscopy (SEM). The image and fractal analysis of micrographs was carried out with a MATLAB ${ }^{\circledR}$ code and Benoit ${ }^{\mathrm{TM}}$ Fractal Software.

\section{A MICROSCOPIC STUDY OF THE WORKPIECE AT THE TOOL-CHIP INTERFACE}

A post-mortem study was conducted to determine the nature of the work material adhering to the tool rake face. Earlier research $[2,3,7]$ indicates the speed as the major factor influencing the frictional contact geometry between the tool and work material. Hence, for the experiments, four speeds were used to cut each of the alloys Al 2024-T351 and Al 6061-T6. The rest of the cutting parameters were controlled for all cutting experiments.

The rake faces of the tools used for cutting were imaged by SEM at a magnification of $50 \times$. The actual areas of the images are $1580 \mu \mathrm{m} \times 1580 \mu \mathrm{m}$. Images were saved as 1024 pixel $\times 1024$ pixel grey-scale images. Hence, the area of one pixel on the image is equivalent to $(1580 / 1024)^{2} \mu \mathrm{m}^{2}$. The backscattered SEM image is based on the molecular weight of the material. Materials with higher molecular weight are of lighter grey shade than the elements with low molecular weight. The brightness and contrast of the images can be set on the scanning electron microscope; this results in white areas for the tungsten carbide tool and aluminium, and other elements with a lighter molecular weight than tungsten carbide are seen in shades of grey. The digital images are modified using Adobe Photoshop ${ }^{\circledR}$ to remove grey spots (traces of work material) from the image which results from work material dust during cutting that has been deposited on the tool. Grey areas represent the sticking region on the tool and the white area surrounded by the grey areas is considered to be sliding. Very-light-grey areas are also considered as sliding areas as aluminium on these spots is present in a very thin layer (less than $0.5 \mu \mathrm{m}$ ) and SEM detects the tool material tungsten carbide through aluminium, as shown in Fig. 1.

Since the boundaries of the contact geometry between the tool and chip are defined by fractals, the areas cannot be calculated by Euclidean geometric equations. For this purpose a program was written in MATLAB ${ }^{\circledR}$ to identify the grey shade of each pixel, to categorize them into one of the three regions (sticking, sliding, and background), and to count the number of pixels present in each region. Knowing the number of pixels in each region the areas of sticking and sliding can be identified as shown in Fig. 2. Figure 2(a) shows the backscattered image for Al 2024 at a cutting speed of $152 \mathrm{~m} / \mathrm{min}$, a feed rate of $0.183 \mathrm{~mm} / \mathrm{rev}$, and a depth of cut of $0.508 \mathrm{~mm}$. The code also generates separate images for sticking, sliding, and total contact area, which were used to compute the fractal dimension using Benoit ${ }^{\mathrm{TM}}$ software by the box-counting technique. Figure 2(b) represents the total contact area with sliding areas in grey and sticking areas in black as calculated by the MATLAB ${ }^{\circledR}$ code based on the grey scale defined in the code by the user. Separate images for sliding and sticking areas were generated (Figs 2(c) and (d) respectively) to facilitate the computation of fractal dimension for sticking and sliding zones.

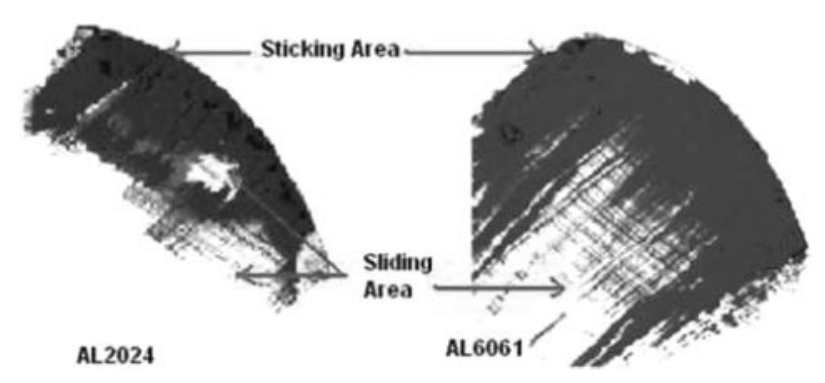

Fig. 1 Areas of sticking and sliding 


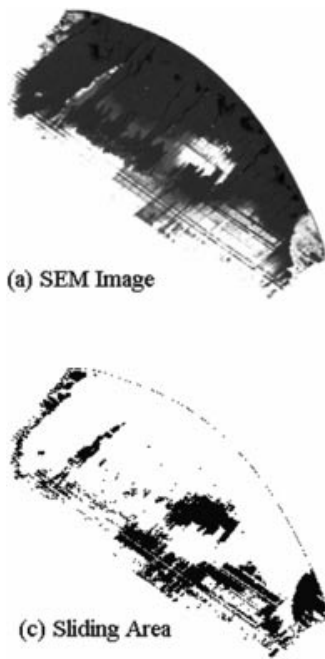

(b) Sticking and Sliding Areas
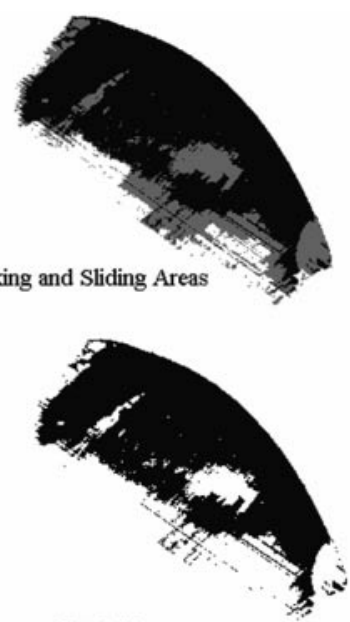

(d) Sticking Area

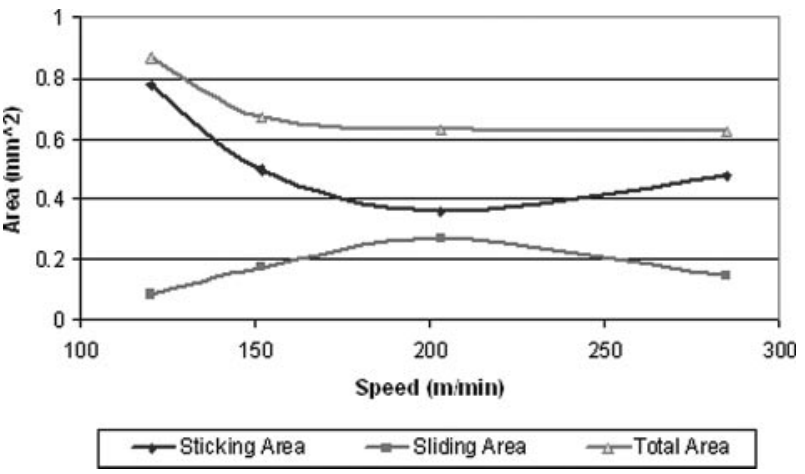

Fig. 3 Computed area values versus cutting speed for Al 2024

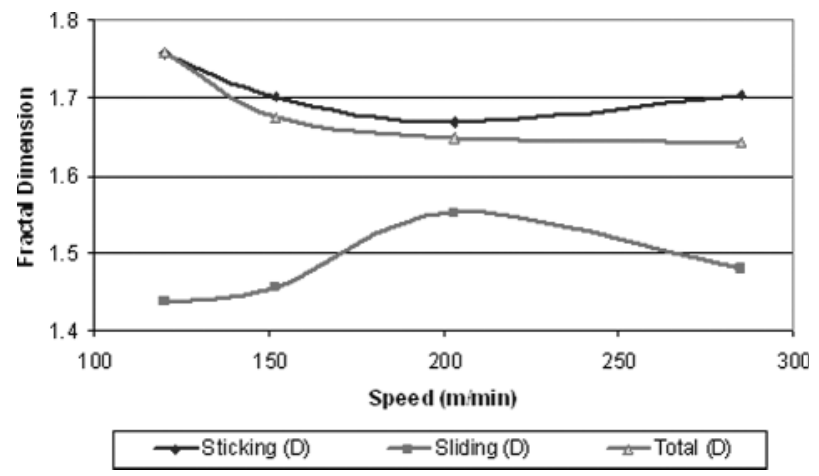

Fig. 4 Computed fractal dimensions versus cutting speed for Al 2024

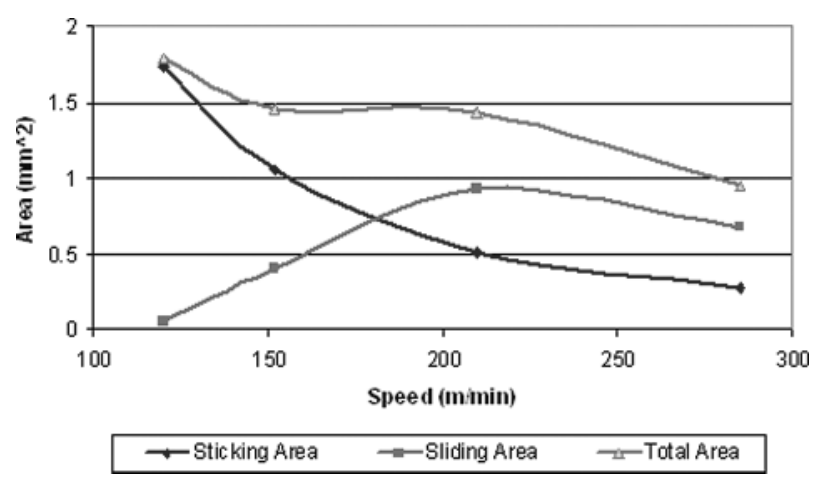

Fig. 5 Computed area values versus cutting speed for Al 6061

et al. [2]. This indicates that each material has a characteristic interaction with the tool under specific cutting conditions. Although the total area of contact is reduced, the plots show an increase in sliding area and decrease in sticking area with increase in the cutting speed. Very low speeds result in heavy buildup, and there is negligible sliding. At these speeds the material behaves in a totally different manner from that at normal cutting conditions. The fractal dimensions for all the calculated areas follow similar trends as the variation in the areas, indicating a relationship between the two. 


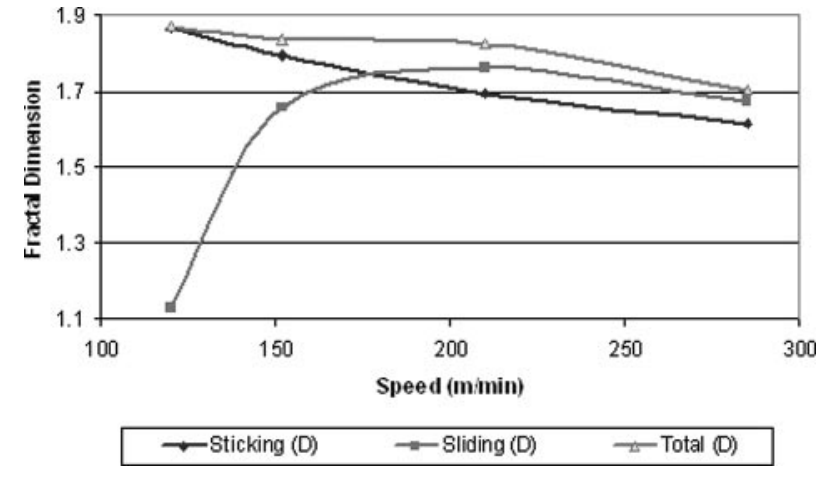

Fig. 6 Computed fractal dimensions versus cutting speed for $\mathrm{Al} 6061$

Table 3 Composition of the work materials [8]

\begin{tabular}{ll}
\hline Material & Composition (\%) \\
\hline Al 2024-T351 & $\mathrm{Si}, 0.50 ; \mathrm{Fe}, 0.50 ; \mathrm{Cu}, 4.90 ; \mathrm{Mn}, 0.90 ;$ \\
& $\mathrm{Mg}, 1.50 ; \mathrm{Cr}$ 0.10; Zn, 0.25; Ti 0.15 \\
Al 6061-T6 & $\mathrm{Si}, 0.80 ; \mathrm{Fe}, 0.70 ; \mathrm{Cu}, 0.40 ; \mathrm{Mn}, 0.15 ;$ \\
& $\mathrm{Mg}, 1.20 ; \mathrm{Cr}, 0.35 ; \mathrm{Zn}, 0.25 ; \mathrm{Ti}, 0.15$
\end{tabular}

For modelling interfacial frictional condition at the secondary shear zone, it is important to consider the changes in work material structure and physical properties during cutting. These tools were further analysed for physical changes in the work material using SEM by analysing the composition at different spots of the build-up. The commercially available aluminium alloys $\mathrm{Al} 2024$ and $\mathrm{Al} 6061$ are heat treated, quenched, and artificially aged to obtain the required homogeneous mechanical properties. The chemical compositions of $\mathrm{Al} 2024$ and $\mathrm{Al} 6061$ are given in Table 3. Al 2024 is an Al-Cu alloy and $\mathrm{Al} 6061$ is an Al-Mg-Si alloy. As aluminium is a soft material, it gains its strength mainly from the presence of the fine hard precipitates present, which obstruct the movement of dislocations in the material. Heat treatment and quenching of the alloy cause an unstable supersaturated solid solution to form and prevent the formation of large precipitates in it. These alloys are then aged at an elevated temperature, allowing the formation of fine precipitates in the alloy to impart strength to the material [9, 10]. Precipitates of $\mathrm{CuAl}_{2}$ and $\mathrm{Mg}_{2} \mathrm{Si}$ formed during age hardening are mainly responsible for the increase in strength of all $\mathrm{Al}-\mathrm{Cu}$ and $\mathrm{Al}-\mathrm{Mg}-\mathrm{Si}$ alloys respectively.

The material adhering to the tool is subjected to extreme pressures and temperatures, causing considerable material changes in terms of composition and properties. The work material on the rake face was analysed by SEM. The build-up on the rake face of the tool shows that the sticking work material has two distinct shades of grey. The front end of the (a)

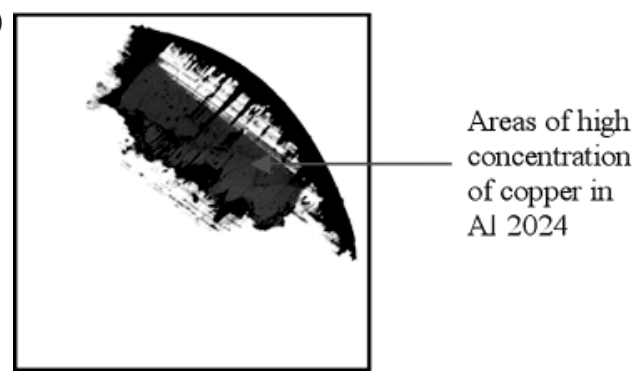

(b)

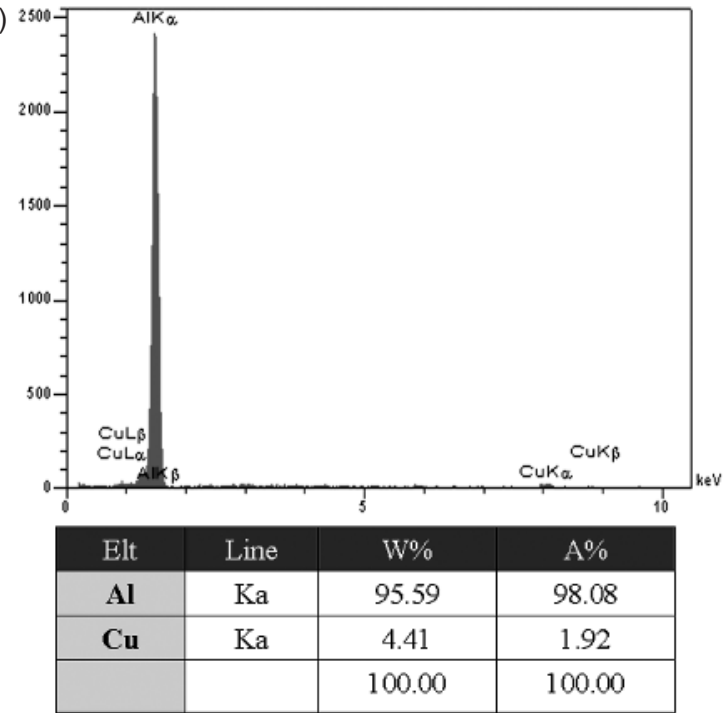

(c)

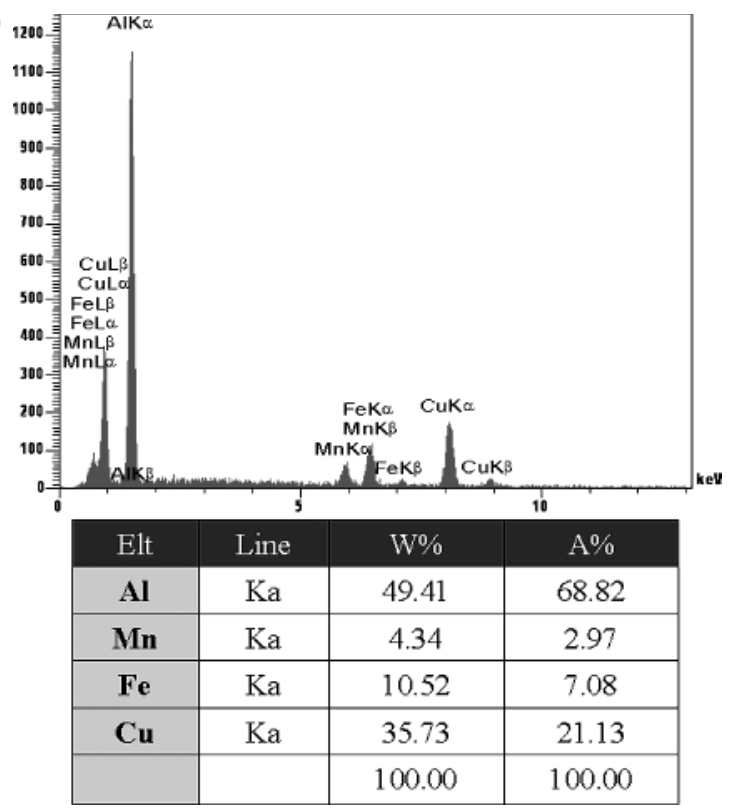

Fig. 7 (a) Backscattered image from SEM; (b) element scan and composition of dark-grey areas; (c) element scan and composition of light-grey areas

sticking material is dark grey and the latter part is a lighter shade in the backscattered image, indicating a higher molecular weight, as seen in Fig. 7(a). The composition of the front and back parts of the builtup areas are given in Figs 7(b) and (c) respectively. 


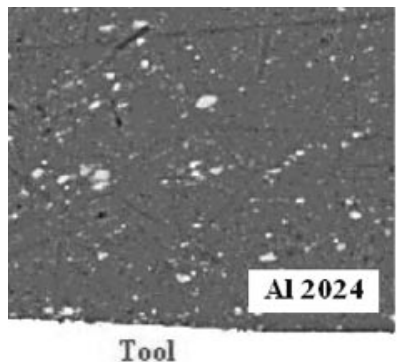

a

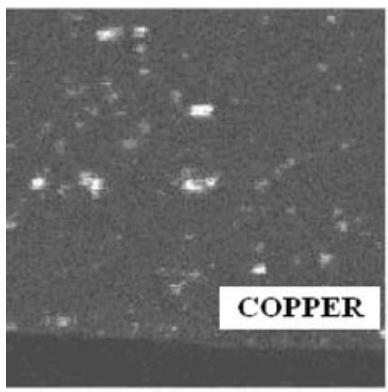

C

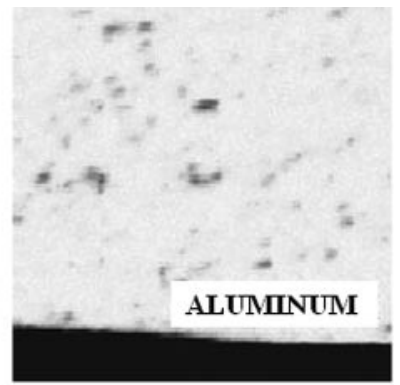

b

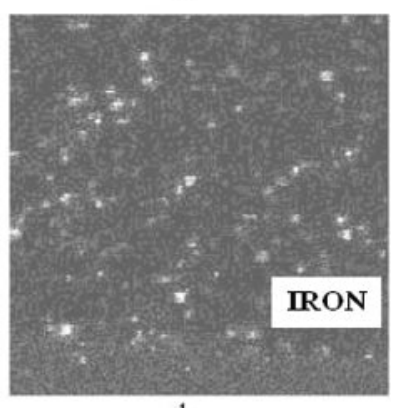

d
Fig. 8 Backscattered image of cross-sectional views at the tool-chip interface for Al 2024

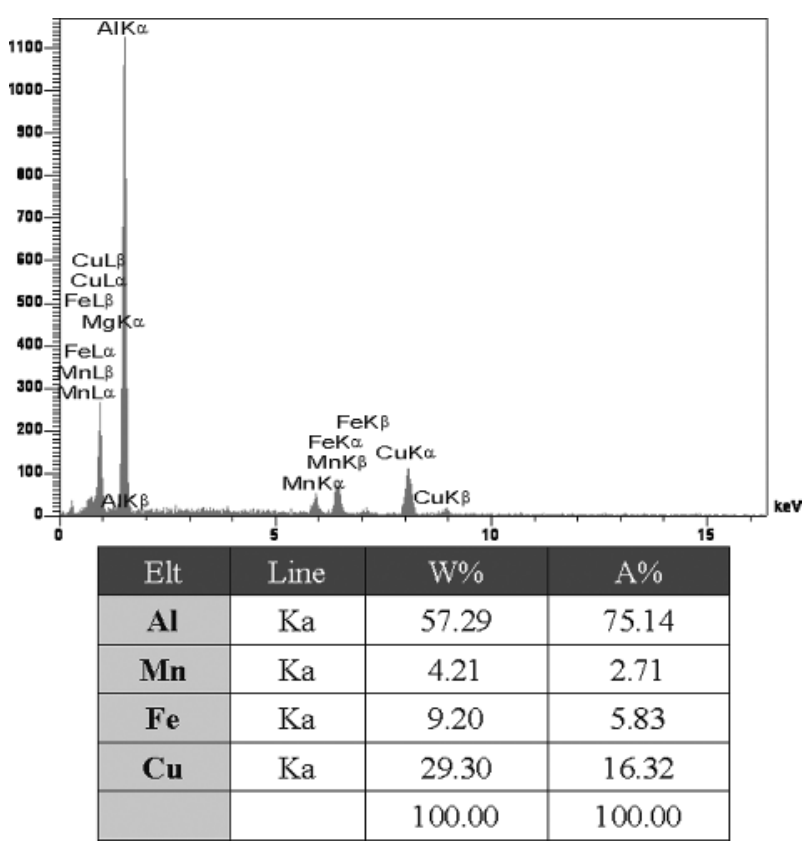

Fig. 9 Element analysis of white spots in $\mathrm{Al} 2024$

The analysis of material composition indicates that the light-grey area shows a higher copper concentration of $35.73 \mathrm{Wt} \%$ (Fig. 7(c)) compared with the dark-grey area in the front edge (4.41 Wt\%) (Fig. 7(b)). This indicates that the heavier and hard precipitates with higher melting point are left sticking to the tool whereas the aluminium is removed together with the chip once it reaches a plastic state, owing to high load and temperature. Such a phenomenon was not observed for $\mathrm{Al} 6061$ on the surface of the build-up.

In order to investigate the built-up material characteristics at the subsurface level these inserts were sectioned through the cutting area in the direction of chip flow to reveal the cross-section of the buildup on the tool. The samples were embedded in epoxy resin and polished to reveal the details of the sticking material. A backscattered image of the section of Al 2024 showed heterogeneity with large bright spots in the material (Fig. 8(a)). The analysis of these spots revealed a high concentration of copper and iron, as shown in Fig. 9.

An element mapping for aluminium, copper, and iron was performed and it is shown in Figs 8(b), (c), and (d) respectively. All aluminium alloys produced commercially contain insoluble iron and silicon [9]. The iron is present in the form of $\mathrm{FeAl}_{3}$ in the material in the form of small precipitates. As the work material on the rake face attains the recrystallization temperature and does not undergo quenching, $\mathrm{CuAl}_{2}$ precipitates and forms into large precipitates. This phenomenon [10] is shown in Fig. 10. This results in a material with different properties from those of the original work material. The formation of large precipitates in the $\mathrm{Al}-\mathrm{Cu}$ alloy will result in a weaker alloy as the precipitates are less likely to prevent dislocation and the material can easily dislocate, avoiding the hard particles.

Al 6061 showed different characteristics from those of Al 2024. All the experiments with Al 6061 showed high concentrations of magnesium, chromium, and iron at the tip of the tool (Fig. 11(a)). The element mapping for aluminium, iron, and magnesium at the tip is given in Figs 11(b), (c), and (d) respectively. This is due to the heating effect under a high stress and strain that result in the deposition of hard precipitates in a specific zone of the build-up.

The material behaviour under a high temperature, high stress and high strain rate are different from the influence exerted by a high temperature only. Severe cutting conditions make the prediction of the behaviour of the alloys difficult. Each alloy will have its own characteristic behaviour under cutting conditions that can be determined by a post-mortem study of the build-up. It remains to be seen how the predictability of the interface mechanics is influenced by the material composition and structure as well as by the severity of the cutting conditions.

\section{TIME-DEPENDENT CUTTING EXPERIMENTS}

To prove the dynamic characteristics of the sticking and sliding areas, time-dependent dry oblique turning was carried out with the Al 2024-T351 work material with an uncoated tungsten carbide cutting 


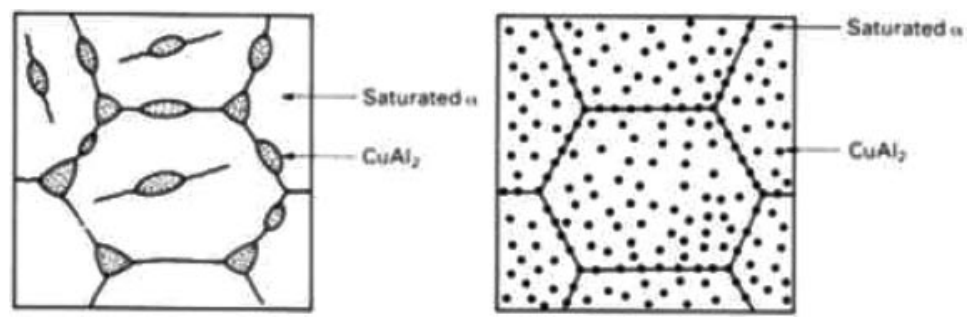

Fig. 10 Microstructure of Al 2024 produced by (a) slow cooling and (b) fast cooling (adapted from reference [10])

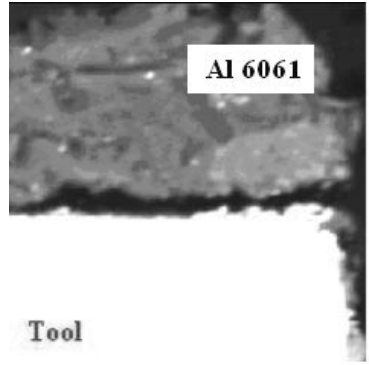

a

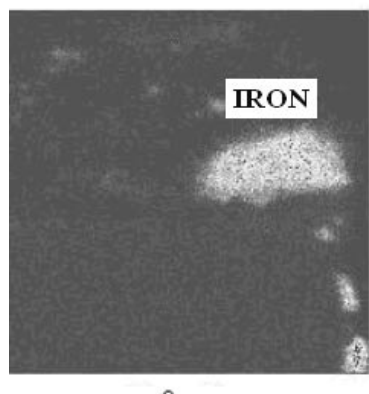

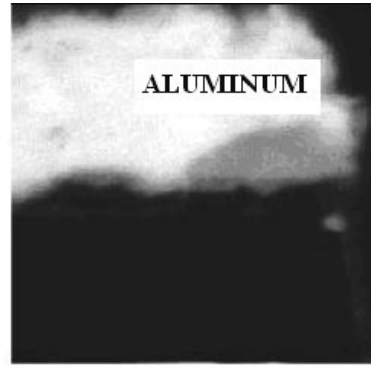

b

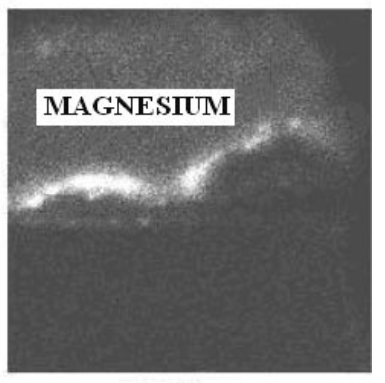

d

Fig. 11 Backscattered images of cross-sectional views at the tool-chip interface for Al 6061

tool. The cutting experiments were performed at $558 \mathrm{r} / \mathrm{min}(195-216 \mathrm{~m} / \mathrm{min})$ and at a feed rate of $0.183 \mathrm{~mm} / \mathrm{rev}$. The depth of cut was $0.508 \mathrm{~mm}$. The time durations of each cut, corresponding cutting speeds, and SEM picture descriptions are given in Table 4. The cutting time is varied from 20 to $360 \mathrm{~s}$ in increments of 20 and $30 \mathrm{~s}$. At the end of the experiments, tool surface micrographs were obtained by SEM. Figure 12 shows the micrographs at different cutting times. SEM images show sticking and sliding areas on the tool surface very clearly.

Elemental mapping analysis was performed to verify the areas of sticking and sliding (Fig. 7). The areas of sticking and sliding do not show Euclidean characteristics, as mentioned earlier. The same procedure mentioned in the previous section was used to compute the exact area values and corresponding fractal dimensions. Table 5 gives the exact values of sticking, sliding, and total areas and corresponding fractal dimensions. The variations in these variables are shown in Fig. 13, graphically. The total contact area shows an increase with a fluctuation. With

Table 4 Details of the time-dependent cutting experiments for $\mathrm{Al} 2024$

\begin{tabular}{rllr}
\hline Time (s) & Diameter $(\mathrm{mm})$ & $\begin{array}{l}\text { Cutting speed } \\
(\mathrm{m} / \mathrm{min})\end{array}$ & $\begin{array}{c}\text { Labelling } \\
\text { in Fig. 12 }\end{array}$ \\
\hline 20 & 111.4 & 195.3 & $20 \mathrm{sec}$ \\
40 & 112.4 & 197.0 & $40 \mathrm{sec}$ \\
60 & 113.4 & 198.8 & $60 \mathrm{sec}$ \\
80 & 114.5 & 200.7 & $80 \mathrm{sec}$ \\
90 & 121.4 & 212.8 & $90 \mathrm{sec}$ \\
120 & 116.6 & 204.4 & $120 \mathrm{sec}$ \\
150 & 117.6 & 206.3 & $150 \mathrm{sec}$ \\
180 & 122.4 & 214.6 & $180 \mathrm{sec}$ \\
240 & 118.7 & 208.2 & $240 \mathrm{sec}$ \\
270 & 123.4 & 216.4 & $270 \mathrm{sec}$ \\
300 & 119.8 & 209.9 & $300 \mathrm{sec}$ \\
360 & 121.4 & 212.8 & $360 \mathrm{sec}$ \\
\hline
\end{tabular}

increasing cutting time the temperature increases and more chip material sticks on the surface of the tool. The softer the material becomes, the more it spreads on the surface. On the other hand, as adhesion progresses, it breaks away at certain time periods and is removed by the chip, which is responsible for this fluctuation. The same fluctuations can be seen for the sliding and sticking areas. The whole picture also supports the idea of the dynamic variation in frictional boundary conditions at the interface during cutting.

Another interesting observation is that the fractal dimension and area value of sliding and total areas demonstrate similar variations throughout the cut period, as shown in Figs 14 and 15 respectively. Further study showed that Mandelbrot's [12] areaperimeter relation can be applied for the sliding area of contact. Since the variations in both fractal dimension and area values show similar characteristics, an average perimeter-area-fractal dimension relationship has been developed for sliding and total areas, for mathematical modelling. The area-perimeter relationships for the sliding and total areas can be rewritten as

$$
\begin{aligned}
A_{\mathrm{sl}} & =P_{\mathrm{sl}}^{2 / D_{\mathrm{sl}}} \\
A_{\mathrm{t}} & =P_{\mathrm{t}}^{2 / D_{\mathrm{t}}}
\end{aligned}
$$

where $A_{\mathrm{sl}}$ is the area, $P_{\mathrm{sl}}$ is the perimeter, and $D_{\mathrm{sl}}$ is the fractal dimension of the sliding area, and $A_{\mathrm{t}}$ is 


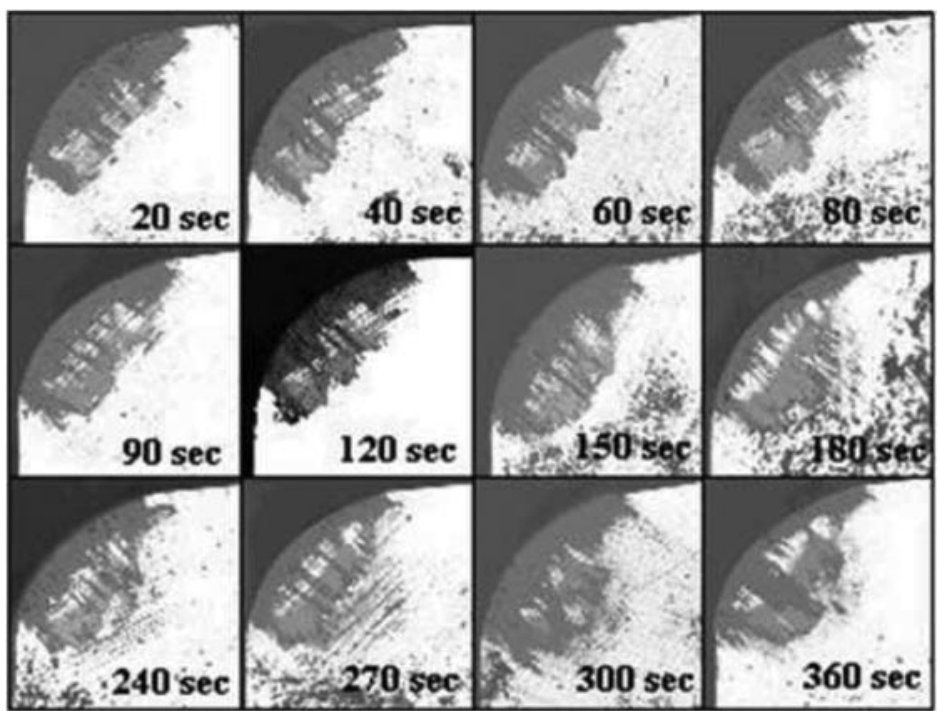

Fig. 12 Scanning electron micrographs of tool-chip contact area at different cutting times for Al 2024

Table 5 Computed area values and fractal dimensions of contact zones for $\mathrm{Al} 2024$

\begin{tabular}{|c|c|c|c|c|c|}
\hline Time (s) & $\begin{array}{l}\text { Sticking area } \\
\left(\mathrm{mm}^{2}\right)\end{array}$ & $\begin{array}{l}\text { Sliding area } \\
\left(\mathrm{mm}^{2}\right)\end{array}$ & $\begin{array}{l}\text { Contact area } \\
\left(\mathrm{mm}^{2}\right)\end{array}$ & $\begin{array}{l}\text { Fractal dimension } \\
\text { of sliding zone }\end{array}$ & $\begin{array}{l}\text { Fractal dimension } \\
\text { of contact zone } \\
\end{array}$ \\
\hline 20 & 0.4300 & 0.1448 & 0.5748 & 1.565 & 1.897 \\
\hline 40 & 0.4087 & 0.1732 & 0.5819 & 1.599 & 1.893 \\
\hline 60 & 0.3955 & 0.1898 & 0.5853 & 1.653 & 1.891 \\
\hline 80 & 0.3768 & 0.2134 & 0.5902 & 1.639 & 1.885 \\
\hline 90 & 0.3598 & 0.2637 & 0.6235 & 1.670 & 1.881 \\
\hline 120 & 0.3403 & 0.2050 & 0.5453 & 1.663 & 1.870 \\
\hline 180 & 0.3525 & 0.3612 & 0.7137 & 1.743 & 1.880 \\
\hline 240 & 0.2874 & 0.3391 & 0.6265 & 1.705 & 1.836 \\
\hline 270 & 0.3576 & 0.3943 & 0.7519 & 1.718 & 1.875 \\
\hline 300 & 0.5654 & 0.2300 & 0.7954 & 1.632 & 1.909 \\
\hline 360 & 0.4193 & 0.2500 & 0.6693 & 1.671 & 1.899 \\
\hline
\end{tabular}

the area, $P_{\mathrm{t}}$ is the perimeter, and $D_{\mathrm{t}}$ is the fractal dimension of the total area. Taking the logarithm of each side and rearranging the terms, the perimeters of the sliding and total areas can be found as

$$
\begin{aligned}
P_{\mathrm{sl}} & =10^{\left(D_{\mathrm{sl}} / 2\right) \log A_{\mathrm{sl}}} \\
P_{\mathrm{t}} & =10^{\left(D_{\mathrm{t}} / 2\right) \log A_{\mathrm{t}}}
\end{aligned}
$$

By averaging the perimeter throughout the cut period, a constant value can be introduced for each cutting material. This value can be defined for each material and experimental condition, i.e. it will be a variable of cutting speed, feed, depth of cut, and material used. $P$ in this model is not only the perimeter value but also a general variable that will be a function of the work material, tool material, rake angle, cutting speed, time, and other cutting variables. Knowing the $P$ value and fractal dimension, the area of sliding and total area of contact can be calculated. The dynamic variation must be, however, suitably verified further. Models for this are under development.
Using the above-mentioned method the characteristic $P$ values for sliding and total area were found for that specific cutting condition and $\mathrm{Al} 2024$ as 0.3137 and 0.6673 respectively. Using these numbers in the area relationship and calculating the fractal dimension from the SEM image will give us the sliding and total areas. The sticking area can be calculated by subtracting the sliding area from the total area. The graphical representations of sliding and total area variation using this method are given in Figs 16 and 17 respectively. Although the values obtained by this method show deviations from the experimental values for different cutting times, it is giving non-fluctuating approximated values for the whole cutting period.

\section{CONCLUSIONS}

Experiments to study the friction mechanism at the tool-chip interface revealed that the workpiece material does not behave homogeneously owing to the 


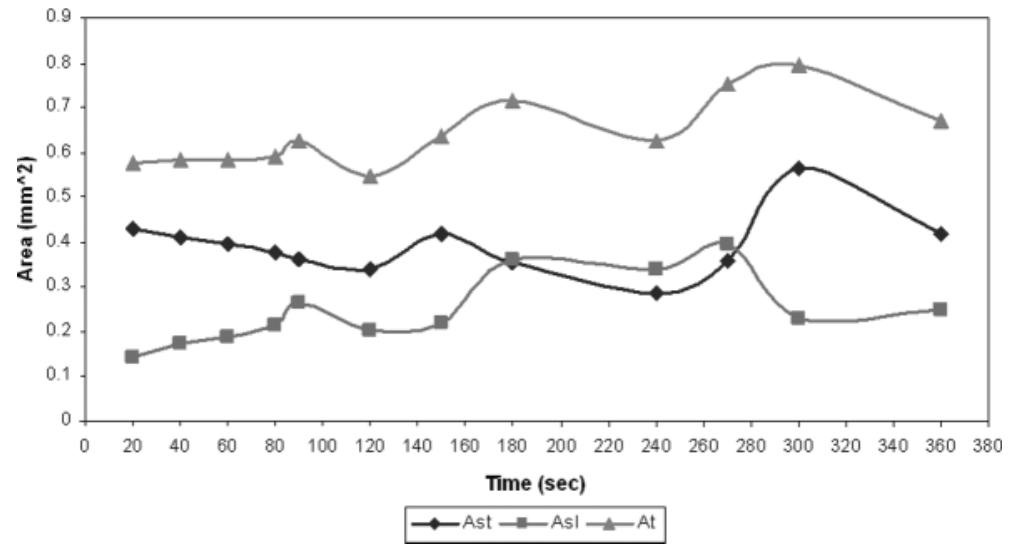

Fig. 13 Graphical representation of the variations in the sticking area, sliding area, and total area of contact during cutting for $\mathrm{Al} 2024$

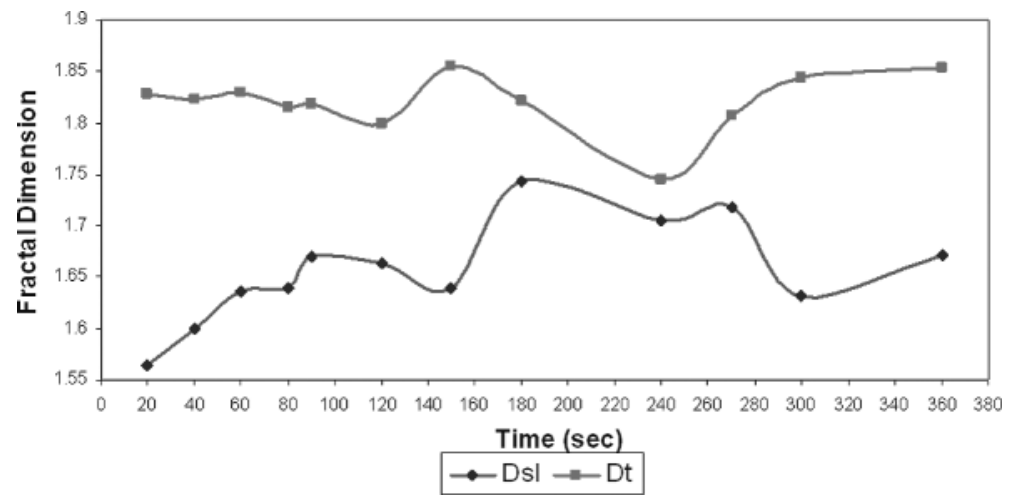

Fig. 14 Graphical representation of the variations in the fractal dimensions of the sliding area and total area during cutting for $\mathrm{Al} 2024$

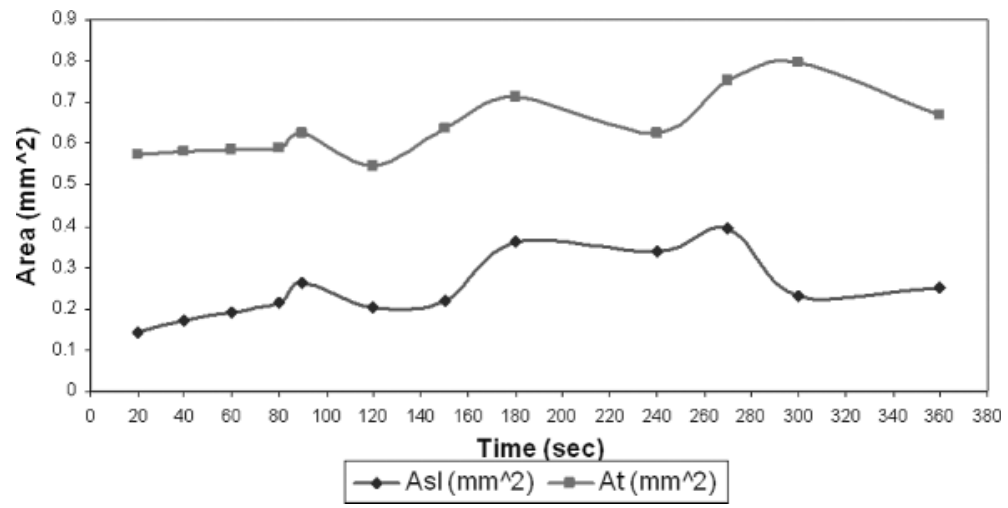

Fig. 15 Graphical representation of the variations in the sliding area and total area during cutting for Al 2024

undetermined distribution of stresses and temperatures at the interface. Under severe cutting conditions the bond strength at the tool-chip interface is very difficult to determine without a scale-based analysis of the contacts. Further study should be performed to determine the relative strength of bonds and adhesion strengths. By image analysis of scanning electron micrographs of the cutting interface, it is possible to find the exact dimensions of sticking and sliding areas and their fractal dimensions. It has been shown that the fractal dimension and area of sliding show similar patterns throughout a cut. This similarity can be used to determine the area-fractal dimension relationship mathematically based on experimental results with different workpiece materials under different speeds and feed rate conditions. 


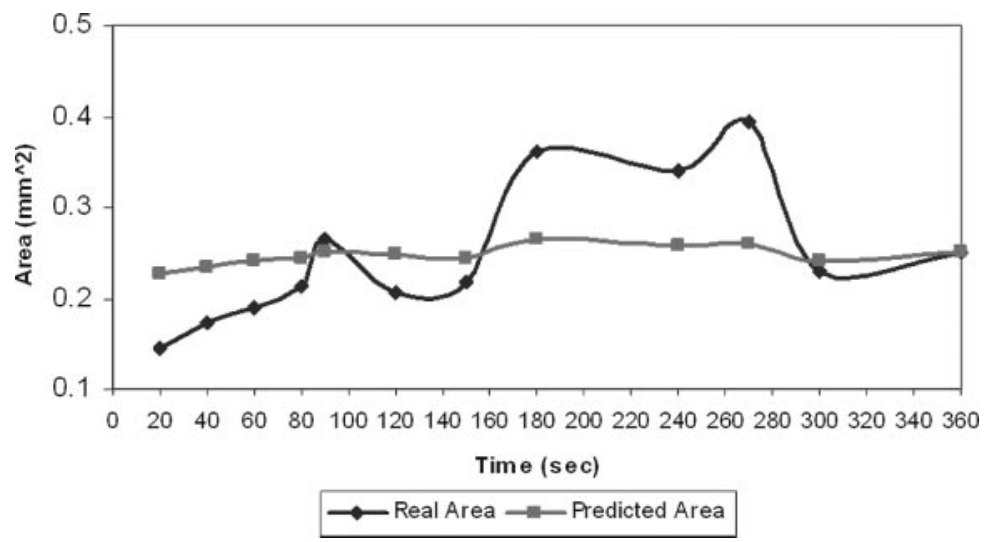

Fig. 16 Graphical representation of the variations in the real and predicted sliding areas of contact during cutting for $\mathrm{Al} 2024$

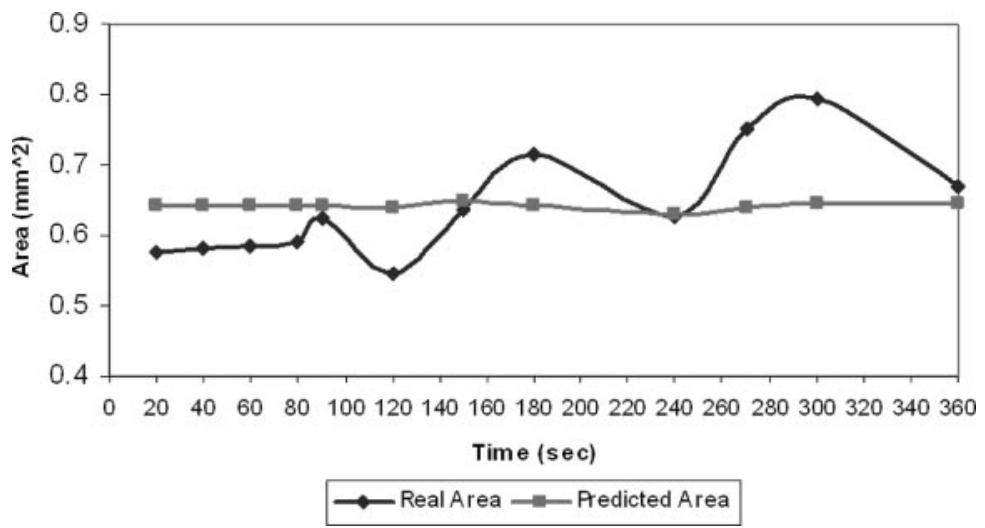

Fig. 17 Graphical representation of the variations in the real and predicted total areas of contact during cutting for Al 2024

A mathematical model for the interface is attempted based on three-dimensional cutting forces and chip flow dynamics. For validation of model assumptions, more experiments will be performed with different material combinations, cutting tool geometries, and cutting conditions. The perimeter of the tool-chip profile is recognized as an important variable for fractal analysis of the interface. The area-perimeter relationship fully developed can lead to a better description of the tool-chip boundary conditions on multiple scales. The main aim of these studies is to determine a basic universal model for quantifying friction characteristics at the tool-chip interface, which will yield more accurate stress and temperature distribution.

\section{ACKNOWLEDGEMENTS}

This work was partly supported by the National Science Foundation (NSF) under grant DMI0140557. The views and opinions expressed in this paper are those of the authors and not necessarily those of the NSF.

\section{REFERENCES}

1 Wright, P. K., Horne, J. G., and Tabor, D. Boundary conditions of the chip-tool interface in machining: comparison between seizure and sliding friction. Wear, 1979, 54, 371-390.

2 Raman, S., Longstreet, A., and Guha, D. A fractal view of tool-chip interfacial friction in machining. Wear, 2002, 253(11-12), 1111-1120.

3 Raman, S. and Chellaperumal, J. Reexamining the machining frictional boundary conditions using fractals. Proc. Instn Mech. Engrs, Part B: J. Engineering Manufacture, 2002, 216(B7), 993-998.

4 Guha, D. and Raman, S. A fractal geometric interpretation of the tool-chip interface in machining. In CD-ROM Proceedings of the Energy Sources Technology Conference and Exhibition (Tribology Symposium) (ETCE 98-4712), Houston, USA, 1998, pp. 1-12.

5 Armarego, E. J. A. and Brown, R. H. The machining of metals, 1969 (Prentice-Hall, Englewood Cliffs, New Jersey).

6 Arseculeratne, J. A., Mathew, P., and Oxley, P. L. B. Prediction of chip flow direction and cutting forces in oblique machining with nose radius tools. Proc. Instn Mech. Engrs, Part B: J. Engineering Manufacture, 1995, 209, 305-315. 
7 Raman, S., Basu, A., and Longstreet, A. Effect of cutting variables on the tool-chip boundary conditions. In CD-ROM Proceedings of the NSF Grantees Conference on Design, manufacturing and industrial innovation, Dallas, USA, 2004, 9 pp.

8 ASM handbook, 10th edition, 1994 (ASM International, Metals Park, Ohio).

9 Smith, W. F. Structure and properties of engineering alloys, 1981 (McGraw-Hill, New York).
10 Ashby, M. F. and Jones, D. R. H. Engineering materials 2: an introduction to microstructures, processing and design, 1986 (Pergamon, Oxford).

11 Zorev, N. N. Interrelationship between shear processes occurring along tool face and on shear plane in metal cutting. In Proceedings of the International Production Engineering Research Conference, 1963, pp. 42-49.

12 Mandelbrot, B. Fractal geometry of nature, 1983 (Freeman, San Francisco, California). 